\title{
Selecting electronic journals
}

\author{
By Helen M. Grochmal
}

\section{Tips for choosing full-text full-image products}

$\mathbf{T}$ he benefits of index sources offering fulltext journal coverage seem to be just what libraries are waiting for-many journals at the touch of a keyboard; cost savings if libraries cancel paper journals available full text or full image on a particular system; direct access from index entry to text without dealing with journals that are out to the bindery, have missing pages, or are shelved differently from the entry in the index source. One may choose a fulltext source for many reasons, but practical considerations need to be taken into account when choosing a product and especially before replacing paper journals with current productswhether provided to the library on magnetic tape, $C D$, or off-site

\section{What do the products currently offer?}

Companies are offering journal titles tied to their indexing/abstracting products. Many titles from the indexed entries may be accessed either full text (usually the article is typed by the company) or full image (the article is scanned or reproduced as published). Some of the most common database offerings for academic libraries are UMI's ProQuest (full image), Information Access's InfoTrac-Expanded Academic ASAP (full text), and EBSCO's MasterFILE (full text). Library access may be offered on magnetic tape or $\mathrm{CD}$ or both, depending on the product. Full-text storage takes up much less space than full-image and influences the way the information is accessed by libraries, however, much information is not reproduced on the full-text source. These companies also of- fer or are planning to offer off-site access to their products. Off-site access is the delivery method that allows libraries access to the product while the databases are located and maintained at a remote site instead of at the library. That way individual libraries will not have to deal with CDs or magnetic tape that take up much local computer data storage space and may be awkward to handle. The way the information is available is changing also; for example, InfoTrac will offer full-image delivery on a selected number of titles on its off-site product while offering full-text coverage on the local product. The products and their coverage are changing rapidly so all details of individual products and licensing agreements are not listed here. Companies should be contacted individually for current practices, hardware requirements, and lists of different subject databases within their systems. However, general descriptions and factors to look for are discussed so potential new customers will know what to ask when considering a system.

\section{What is left out?}

Most of the companies list information not included in their full-text products that is included in the paper journal. Short articles, letters, formulas, pictures, illustrations, book reviews, and miscellaneous types of information are often not part of the product. Cover-to-cover does not always mean what one would want. Information is not always arranged as the author or publisher has published it. Sometimes poetry is typed without any attention to the original spacing and articles are printed without pagination. Text in art periodicals may refer to illustrations not reproduced. Tabular data is often not given. (One source-InfoTrac-CD version-gives a letter grade instead of giving 
the book review from some journals.) Even titles available in full image may leave out parts of individual journals, although indexed articles are scanned in their complete form. A company may have the rights to reproduce only parts of some titles, leaving out book reviews, for example. Some information the library expects to receive may be left out of a system by becoming unavailable or being delayed. Any of the companies may lose the right from a publisher to reproduce a journal, so libraries would have to be prepared for changes out of their control. The companies may also be delayed by contract from including the current issue of a journal in their systems. It should be pointed out that some of these systems drop indexing and full-text journals after a certain time period and this data must be purchased separately. One system routinely drops indexing and journal coverage of titles after three years. Although the information is available at an extra charge, it may be inconvenient to access since it is a separate database.

\section{What system should a library choose?}

The system a library chooses would depend on its needs and budget. The CD full-image databases take up a lot of storage space and a number of CDs must be accommodated. The full-text databases take up less space but much information is lost. Choice would depend on the library's budget, computer capabilities, its reasons for choosing one of these systems, and the list of titles it wishes indexed. Full image may require more steps to handle and be more expensive but may be necessary if the library's purpose in choosing a system is to cancel lowuse paper journals available full image on the indexing source. If a library is choosing a system for its indexing and finds the journal availability to be an adjunct to its collection and not a reason to change its paper holdings, full text might be acceptable, especially if the price is right. After determining the reasons for choosing a system and comparing the systems to each other, anyone interested in purchasing a product of this sort should ask all of the relevant questions of the supplier. The customer should then sit down with the current paper copies of journals and compare the copies page by page with the full-image and/or full-text journals to see exactly what is available on the product and see when the latest copies are placed on the system. (One may also check to see how

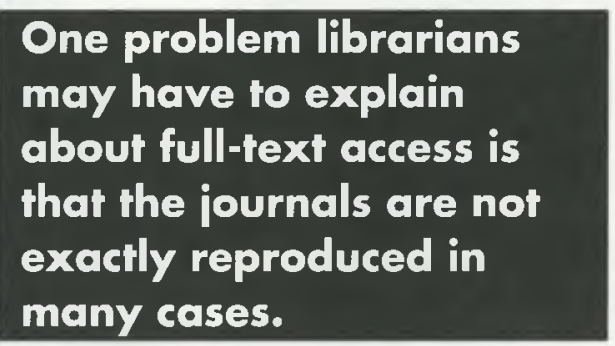

well these new products are indexing/abstracting the original source while one checks the full-text/full-image quality.)

Companies frequently offer their systems on a free trial basis. A trial period as it would actually be used might be worth investigating. Call the customer relations department of the system to see how it maintains support.

\section{Should libraries cancel paper titles?}

Electronic joumals are relatively new and changing often. It would be best if a library could wait to see what is happening with them before cancelling titles. If budget constraints require cancellation of paper journals and the electronic system is taken into consideration in the choice of which paper titles to cancel, titles to be considered may be:

1) low-use titles, especially if the title is available full image and not full text;

2) titles that don't contain illustrations and other types of information that the chosen system does not supply. For example, see if the system includes the short but very important section on queries before cancelling the literary journal Notes and Queries;

3) titles with back issues easily available in case the title is dropped from the system;

4) titles that are not usually read cover-tocover by the academic community for professional or recreational reasons.

\section{What are faculty concerns?}

The journal is a means of formal communication from one scholar to another. Authors carefully proofread each word before publication and editors recheck copy. The main concern of faculty is that the new product will reproduce the original source to a sufficient degree and in a timely enough manner to support research. One problem librarians may have to explain about full-text access is that the journals are not exactly reproduced in many cases. Can the provider be trusted to type the infor-

(Electronic joumals cont. on page 654) 


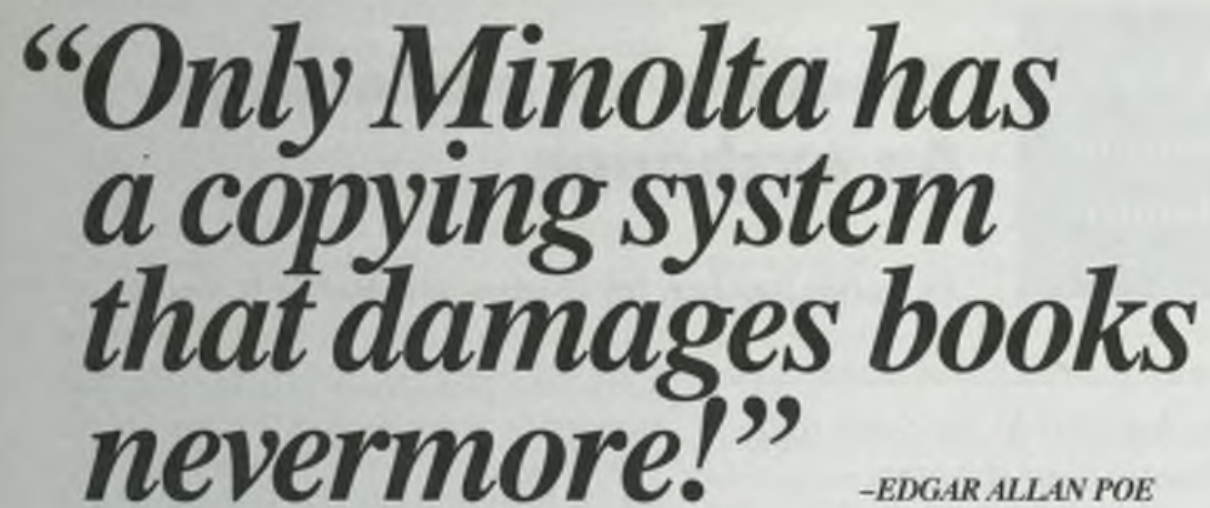

\section{Introducing the Minolta DPCS 3000}

If Poe had to copy his original manuscript of "The Raven" the DPCS 3000 would have him waxing poetic. Because it's the face-up digital publication copying system that copies books gently, simply, quickly.

Thanks to a unique face-up copying design, there's virtually no spine bending or brittle page breaking. Double-page spreads copy without curves or shadowed gutters. Photos and artwork reproduce to critical acclaim. Even 3-D objects are reproduced with precision.

Digital imaging and laser technology make this a high speed operation. Plus, the DPCS 3000 will soon write a new chapter with image storage, fax, e-mail and Internet service capabilities to meet your expanding needs.

Did we tell you about our service and expertise in copying and digital imaging?

We don't want to give the whole story away. Call 1-800-9-MINOLTA for more information about the most novel idea in copying.

Digital Publication Copying System 3000

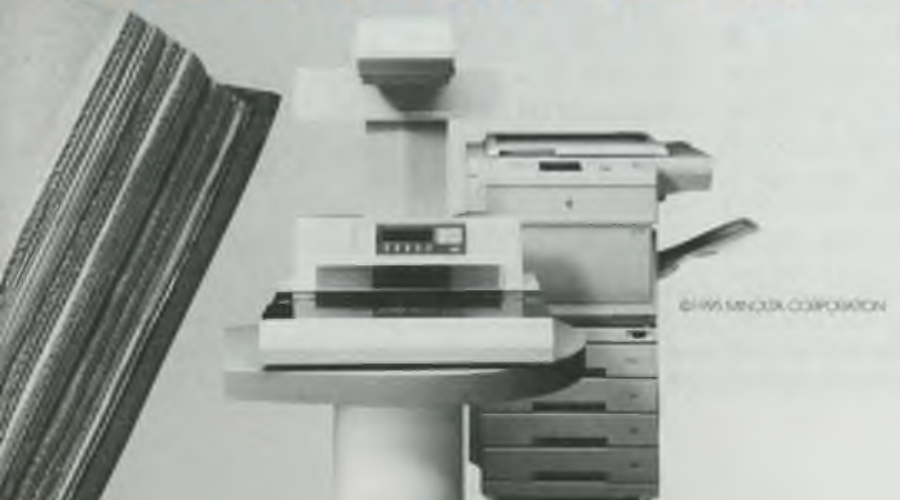

Copiers

Cameras

Faxes

Digital Systems

Document Imaging

Camcorders

Binoculars

Color Sensors

Only from the mind of Minolta

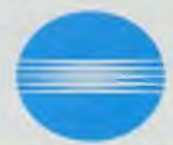

MINOLTA 
Women's Studies Section. Vice-Chair/ChairElect: Bonnie J. Cox, 128 Owsley Ave., Lexington, KY 40502-1526; e-mail: kli111@ukcc.uky. edu.

\section{ACRL divisional committee appointments}

ACRL has 27 standing committees to which appointments may be made. A list appears on the volunteer form at the end of this article. You will find the committees listed with a description of their charges in the ALA Handbook of Organization.

Appointments to ACRL standing committees are made in the spring for terms beginning immediately after the ALA Annual Conference. The Appointments and Nominations Committee recommends to the president-elect of ACRL the names of members who might fill the vacancies. The president-elect makes the final appointments. If you are interested in being considered for an appointment to an ACRL committee, you should complete the ACRL Committee Volunteer Form included with this article and send it to Betsy Baker at the address given on the form before December 15, 1995.

\section{Editorial boards}

ACRL has editorial boards for these six publications: Choice, College \& Research Libraries; College $\&$ Research Libraries News; New Publications; Publications in Librarianship, and Rare Books \& Manuscripts Librarianship.

Appointments to editorial boards are made at the Midwinter Meeting for terms that begin immediately after the ALA Annual Conference. The editors recommend the name of a person to fill the vacancy. The Publications Committee must approve the recommendation, and the president of ACRL makes the appointment.

If you would like to be considered for appointment to an editorial board, contact the editor of the editorial board.

Cboice editor: Irving Rockwood, Cboice, 100 Riverview Center. Middletown, CT 06457; e-mail: irv_rockwood@delphi.com.

College \& Research Libraries editor-designate: Donald E. Riggs, University of Michigan, 818 Hatcher Graduate Library, Ann Arbor, MI 48109-1205; e-mail: driggs@umich.edu

College $\&$ Research Libraries News editor: Mary Ellen Davis, CERL News, ACRL/ALA, $50 \mathrm{E}$. Huron St., Chicago, IL 60611-2795; e-mail: mary.ellen.davis@ala.org.
New publications editor: Hugh Thompson, ACRL/ALA, 50 E. Huron St., Chicago, IL 60611-2795; e-mail: hugh.thompson@ala,org.

Publications in Librarianship editor: Stephen E. Wiberley Jr., University of Illinois at Chicago University Library, P.O. Box 8198, Chicago, IL 60680-8198; e-mail: u30959@ uicvm.uic.edu.

Rare Books \& Manuscripts Librarianship editor: Sidney E. Berger, University of California, University Library, P.O. Box 5900, Riverside, CA 92517-5900; e-mail: spcolseb@ ucrvms.bitnet.

\section{(Electronic joumals cont. from page 633)}

mation correctly if the article is not full image? Citing from an electronic source is another question faculty may raise. Librarians may show new ways to cite articles like this from style manuals. However, it is difficult to cite work that has no pagination and is arranged differently from the paper copy or the electronic arrangement the publisher may have. Faculty may be concerned not about the format of the journal (after all, electronic journals are the way of the future) but the authority of the source if the system has rearranged it on the full-text databases.

\section{Conclusion}

Librarians need to discuss the way electronic journals are being introduced into academic libraries and influence the way the products are being developed. Should accuracy of content take second place to computer storage problems? Is an article whose main content revolves around an illustration worthless if the illustration is left out? For academic librarians, reproduction of an author's exact content and accurate citation are too important to relegate to nonpriority status. Scholarship depends on these factors. Until the day comes when any article is available on demand the way it was originally produced, academic librarians need to emphasize the needs of research and scholars. It is too early to see which products are going to be preferred and what innovations will take place in document delivery. The world of serials is being revolutionized and many improvements are in store. The problems of missing information are already being addressed by providers and this trend should be encouraged. Great care must be taken that librarians influence the electronic journal industry for the better. 